\title{
Edgar Morin e Paulo Freire e suas contribuições para a formação docente e a prática pedagógica
}

\author{
Daniele Saheb Pedroso* \\ Marlene Zwierewicz** \\ Michelle Jordão Machado*** \\ Daniela Gureski Rodrigues**** \\ Helena Castilho Zielinski*****
}

\section{Resumo}

Este estudo objetivou analisar pesquisas realizadas em programas de pós-graduação stricto sensu cujo referencial teórico tenha como base contribuições de Edgar Morin e de Paulo Freire, especificamente sobre os temas formação docente e articualação de práticas pedagógicas a demandas locais e globais. Para tanto, fez-se estudo bibliográfico, com abordagem

* Doutora em Educação pela Universidade Federal do Paraná - UFPR, Professora titular da Pontifícia Universidade Católica do Paraná - PUCPR. e-mail: danisaheb@yahoo.com.br ORCID https://orcid.org/0000-0003-1317-6622

** Doutora em Psicologia pela Universidade Federal de Santa Catarina - UFSC, Doutora em Educação pela Universidade de Jaén - UJA - Espanha, Coordenadora do Mestrado Profissional em Educação Básica - PPGEB, da Universidade Alto Vale do Rio do Peixe - UNIARP. e-mail: marlenezwie@yahoo. com.br. ORCID https://orcid.org/. 0000-0002-5840-1136

*** Doutora e Mestre em Educação pela Universidade Católica de Brasília UCB, Assessora de Educação Básica e Superior na União Marista do Brasil. Coordenadora de cursos de pós-graduação em Educação no IESB. e-mail: michellejm@gmail.com Orcid: https://orcid.org/0000-0001-7643-8293

**** Doutoranda na Pontifícia Universidade Católica do Paraná - PUCPR, Curitiba, Paraná, Brasil. e-mail: dany_gureski@yahoo.com.br ORCID - 00000001-6144-0542

****** Universidade Alto Vale do Rio do Peixe - UNIARP. Mestre em Educação Básica pela Universidade Alto Vale do Rio do Peixe - UNIARP. Docente da Rede Municipal de Ensino de Timbó Grande. Lattes: http://lattes.cnpq. br/9424448179810317. ORCID: https://orcid.org/0000-0002-8718-4468. E-mail:lenacastilho@yahoo.com.br enacastilho@yahoo.com.br 
qualitativa. Desse modo, a pesquisa mapeou teses e dissertações no catálogo da CAPES cujos títulos explicitassem a relação de ambos os autores com a formação docente ou com a prática pedagógica. Nos resultados da análise, destacam-se contribuições dos autores para a compreensão da interdependência entre formação docente e prática pedagógica, com destaque à necessidade de se repensar a perspectiva fragmentada e descontextualizada da educação. Portanto, a pesquisa contribui para a ampliação do diálogo entre os estudos de Morin e de Freire e, além disso, como consequência, para esse debate no âmbito da formação de professores e da prática docente.

Palavras-chave: Edgar Morin; Paulo Freire; Formação docente; Prática pedagógica.

\section{Edgar Morin and Paulo Freire and their contri- butions to teacher education and the pedagogical practice}

\section{Abstract}

This study aimed to analyze research studies from stricto sensu graduate programs whose literature review is based on contributions by Edgar Morin and Paulo Freire specifically on the themes of teacher education and articulation of pedagogical practices with local and global demands. The paper highlights these authors' contributions to teacher education and pedagogical practices related to global and local demands. Therefore, a bibliographic study was carried out with a qualitative approach. Thus, the research mapped theses and dissertations in the CAPES catalog whose titles explained the relationship of both authors with teacher training or with pedagogical practice. In the analysis results, the authors' contributions to the understanding of the interdependence between teacher education and pedagogical practice stand out, with emphasis on the need to rethink the fragmented and decontextualized perspective of education. Therefore, the research contributes to the expansion of the dialogue between Morin's and Freire's studies and, in addition, as a consequence, to this debate in the context of teacher education and teaching practice.

Keywords: Edgar Morin; Paulo Freire; Teacher education; Pedagogical practices. 


\section{Edgar Morin y Paulo Freire, y sus aportes para la formación docente y la práctica pedagógica}

\section{Resumen}

Este estudio tuvo el objetivo de analizar investigaciones realizadas en programas de postgrado stricto sensu cuyo marco teórico tenga como base contribuciones de Edgar Morin y Paulo Freire específicamente en los temas de formación docente y articulación de prácticas pedagógicas con demandas locales y globales. Por tanto, se realizó un estudio bibliográfico, de abordaje cualitativo. Así, la investigación mapeó tesis y disertaciones en el Catálogo de la CAPES que incluyeran los nombres de ambos autores individualmente como descriptores, pero que también presentaran en sus títulos una relación entre estos y la formación docente o con la práctica pedagógica. En los resultados del análisis se destacan los aportes de los autores a la comprensión de la interdependencia entre la formación docente y la práctica pedagógica, con énfasis en la necesidad de repensar la perspectiva fragmentada y descontextualizada de la educación. Por tanto, la investigación contribuye a ampliar el diálogo entre los estudios de Morin y Freire y, además, como consecuencia, a este debate en el contexto de la formación docente y la práctica docente.

Palabras clave: Edgar Morin; Paulo Freire; Formación docente; Práctica Pedagógica.

\section{Introdução}

Nascidos em 1921, Edgar Morin e Paulo Freire se transformaram em duas referências para a educação, tanto por suas reflexões sobre a necessidade de mudanças nessa área como por terem proposto alternativas para colaborar com esse processo. Enquanto Edgar Morin defendeu o pensamento complexo e a articulação da prática pedagógica ao contexto local e global, Paulo Freire propagou a educação emancipadora e sua dinamização por meio de projetos com ênfase em temas geradores. Assim, as décadas em que esses autores ofereceram tais contribuições tornaram-se marcos de resistência - à barbárie, às injustiças e à exclusão social - e de persistência - em uma educação comprometida com a vida.

Por isso, transitar pelas discussões feitas por esses dois expoentes, analisando seus reflexos em pesquisas da pós-graduação 
stricto sensu, foi a condição mobilizadora deste artigo. Dentre essas pesquisas, houve destaque para as que trataram de formação docente e práticas pedagógicas articuladas às demandas locais e globais. Em razão disso, constituiu-se o objetivo deste estudo.

Nesse processo, por meio da pesquisa bibliográfica e da abordagem qualitativa, acessou-se o Catálogo de Teses e Dissertações da CAPES $^{1}$ e foram selecionadas 14 pesquisas. Para essa seleção, a metodologia consistiu em considerar como descritores os nomes de Edgar Morin e de Paulo Freire individualmente; ademais, os títulos deveriam apresentar uma relação entre as reflexões dos autores e a formação docente ou a prática pedagógica. Assim, este artigo apresenta as principais reflexões de ambos os autores sobre a educação e os resultados da análise das pesquisas selecionadas.

Desse modo, espera-se que este estudo colabore com o reconhecimento da relevância da formação docente para a metamorfose da prática pedagógica. Além disso, que contribua para reduzir a lacuna entre as universidades e as escolas, conforme apontado por Nóvoa (2017), em relação à necessidade de contextualização da formação inicial e continuada no sentido de seu engajamento com as problemáticas locais e globais.

\section{A religação entre formação docente e prática pedagógica}

O cenário atual é marcado por profundas mudanças na área da educação. Uma dessas alterações foi causada pela pandemia de Sars-CoV-2, que impôs isolamento físico e ditou às instituições educacionais e, consequentemente, aos gestores e docentes a urgência de adaptação pedagógica do espaço presencial para o remoto. Entretanto, percebeu-se que, em alguns casos, as transições dos processos educativos ocorreram com a simples virtualização da prática pedagógica tradicional, com a utilização de ferramentas digitais como metodologias de transmissão e recepção. Portanto, não foram agregadas bases epistemológicas para um novo cenário,

https://catalogodeteses.capes.gov.br/catalogo-teses/\#!/ 
capazes de romper com o paradigma linear, cartesiano, de reprodução de ideias e de conteúdos.

Mas, mesmo antes da pandemia, Nóvoa (2017, p. 2) já afirmava que o referencial escolar “[...] está em desagregação. Não se trata de uma crise, como muitas que se verificaram nas últimas décadas. Trata-se do fim da escola, tal como a conhecemos, e do princípio de uma nova instituição, que certamente terá o mesmo nome, mas que será muito diferente". Nesse sentido, Nóvoa (2019) defende uma formação continuada que envolva o contexto de atuação docente e que favoreça a reflexão conjunta e o desenvolvimento de trabalhos coletivos, com a participação de todos os profissionais que fazem parte da comunidade escolar. Para ele, "[...] a metamorfose da escola acontece sempre que os professores se juntam em coletivo para pensarem o trabalho, para construírem práticas pedagógicas diferentes, para responderem aos desafios colocados pelo fim do modelo escolar [...]" (p. 11) que persiste tanto na Educação Básica como no Ensino Superior.

Essa reflexão de Nóvoa (2017), aliada à situação atual, incita ao enfrentamento dos problemas por meio de conhecimentos emergentes e não lineares, que requerem abordagens fundamentadas em novos paradigmas da ciência e práticas pedagógicas comprometidas com as exigências do contexto. Essas práticas, segundo Moraes e Torre (2007), solicitam, no processo de aprendizagem individual e coletivo, a articulação adequada e simultânea entre as dimensões construtiva e informativa.

Portanto, precisa-se aprender e ensinar de forma que essas dimensões contribuam para o desenvolvimento das pessoas e de suas relações com os outros e com o meio. Para isso, podemos pensar na dinâmica pedagógica conforme proposto por Freire (2019), a qual deve primar por um processo constante de diálogo e de religação de saberes que se influenciam reciprocamente por meio da práxis. Essa dinâmica potencializa os processos reflexivos sobre os diversos saberes e o estabelecimento de diálogo e conexões entre eles, comprometendo-se com aquilo que Morin (2015) define como bem viver. 
Disso decorre a necessidade de ressignificar as metodologias que orientam os processos de formação docente, seja inicial, seja continuada. para que essas possam responder às necessidades fundamentais que permeiam a realidade, contribuindo para a construção de um perfil docente apto para lidar com as incertezas e metamorfoses na escola e na vida. Portanto, tendo em vista a necessidade de tais metamorfoses apresentadas no processo formativo de professores e na prática pedagógica, aproximar o pensamento de Freire e Morin se constitui numa importante contribuição.

\section{Edgar Morin e Paulo Freire: singularidades e aproximações}

Analisando a realidade atual, especialmente no contexto brasileiro, observa-se o quanto velhos paradigmas voltam a influenciar a forma de pensar e agir de uma parte significativa da população. Em relação à educação, a persistência em paradigmas reducionistas reflete diretamente na formação das novas gerações e dificulta sua mobilização no enfrentamento das adversidades que se avolumaram com pandemia da covid-19.

Isso pode ser percebido ao serem observadas práticas pedagógicas que ainda persistem em estratégias de ensino e aprendizagem que dificultam a aprendizagem e o desenvolvimento integral dos estudantes. Como exemplo, pode-se citar a classificação por faixa etária, que os posiciona em classes seriadas, numerosas e numeradas, por vezes em espaços reduzidos nas carteiras. Essa situação gera imobilidades físicas, redução de suas falas e impedimento de pensar, sentir e agir de maneira integrada. Assim, a escola ainda persiste como reprodutora de conhecimentos processados linearmente e de discursos pedagógicos autoritários, em vez de utilizar processos interativos de construção de conhecimentos e valorização do protagonismo.

Tal educação que não considera o estudante em sua integralidade e complexidade foi denominada por Freire (2019) como "domesticadora" e "bancária". Desse modo, Freire disse de uma 
prática pedagógica que "deposita" no estudante informações, dados e fatos, pensando ingenuamente que com isso ele será capaz de construir conhecimento e afrontar seu destino histórico. Por sua vez, o docente é quem detém o saber, a autoridade que dirige o processo e o modelo a ser seguido.

Por isso, diante da persistência dessas práticas pedagógicas fragmentadas e descontextualizadas, Morin (2018) defende a necessidade de uma reforma urgente com caráter epistemológico e reflexivo, a qual deverá atingir o plano do conhecimento. Tal reforma do pensamento deve ser capaz de produzir relações entre os conhecimentos, conectando as partes com o todo e o todo com as partes. Epistemologicamente, “[...] trata-se de substituir o paradigma que impõe conhecer por disjunção e redução por um paradigma que exija conhecer por distinção e conjunção" (MORIN, 2013, p. 184). Para o autor, essa reforma propõe um pensamento complexo para servir de base para se tomar consciência das contradições lógicas que devem ser enfrentadas: ordem/desordem, razão/paixão, uno/ múltiplo, bem/mal, ser/saber.

Conhecer esta articulação entre complexidade e educação refletindo sobre ela -, conforme a proposta Morin e junto às bases epistêmicas de Freire, poderá auxiliar os sujeitos implicados na dinâmica da relação educativa a compreender a realidade não apenas sob duas vertentes marcadas pela conjunção "ou”, que exclui possibilidades, mas pela superação dos binarismos entre certo e errado, para, assim, associar categorias e conceitos aparentemente excludentes entre si. Assim, ao buscar o caminho do meio, com base em processos dialógicos, pode-se perceber com maior grau de sensibilidade o que está entre e além de dois polos aparentemente antagônicos.

Para tanto, faz-se necessário apresentar as principais referências que articulam o pensamento complexo na perspectiva de Edgar Morin - em que o fazer pedagógico deve encarar o conhecimento de forma integrada aos contextos e ao planeta, aos sentidos produzidos pelas pessoas, interligando áreas diferentes no desenvolvimento de significados - e as concepções da educação emancipadora 
e libertadora de Paulo Freire - que visa impulsionar os propósitos educacionais capazes de resgatar o ser humano, contribuindo para que este seja um agente transformador de sua realidade.

Segundo Freire (2019), a construção do conhecimento faz-se de forma integrada e interativa. Portanto, não é algo dado e acabado para ser reproduzido, pois conhecer é descobrir e construir. Ainda na concepção desse autor, a busca por conhecimentos é um processo que aproxima o estético, o epistemológico e o social. Trata-se, então, de uma ciência que se elabora em função do crescimento e da evolução do ser humano em sua inteireza (FREIRE, 2013), não em vista da técnica objetiva que desconsidera a consciência.

Para isso acontecer, cabe ao docente planejar atividades com situações problematizadoras em que a metodologia seja potente o suficiente para possibilitar a apreensão de temas geradores e a tomada de consciência dos estudantes sobre suas realidades, seus pensamentos e suas linguagens. Esses temas geradores trazem para o processo educativo a percepção e a visão de mundo dos estudantes. Eles têm o potencial de gerar ações humanas e de provocar e promover discussões (FREIRE, 2019), na medida em que pressupõem a constituição de uma curiosidade epistemológica, necessária aos educandos. Nesse lugar de encontro, não há ignorantes nem sábios absolutos: há homens e mulheres que, em comunhão, buscam saber mais.

Desse modo, o diálogo começa na busca de conteúdo pragmático capaz de emancipar os educandos. Essa emancipação gera o empoderamento, que envolve a maturação do pensamento, isto é, a passagem do pensamento ingênuo para o pensamento crítico, no qual o indivíduo passa a ter consciência crítica, o que favorece a possibilidade de transformação social (FREIRE, 2013).

$\mathrm{Na}$ perspectiva de Morin (2019), o conhecimento se constitui por meio de interações e questionamentos, não por certezas e conteúdos dados. Isso traz indagações sobre o modelo disciplinar e propõe a presença de atitudes que superem a visão racionalista e considerem elementos produtores do conhecimento - o contexto, 
as emoções, os sentimentos, a intuição e a espiritualidade. Nesse processo, é importante destacar que conhecer comporta informações como possibilidades de responder às incertezas, mas o conhecimento não se reduz a informações. $\mathrm{O}$ conhecimento conta com as informações a fim de produzir soluções aos problemas do mundo que afetam a saudável e qualificada vida humana e do planeta.

Dessa forma, percebe-se que a organização do conhecimento em disciplinas mostrou-se nociva à produção de saber. Nela, o isolamento de objetos do conhecimento impede a compreensão do todo e compromete a eficácia da produção científica. Nesse cenário, a transdisciplinaridade, como lembra Nicolescu (2018), surge como possibilidade de transgressão das fronteiras disciplinares em vista de uma abordagem complexa da realidade e de seus fenômenos. Isso ocorre pois ela possibilita o aprender a conviver, que é mais do que tolerar as diferenças, mas dialogar com a harmonia e a desarmonia entre o individual e o social. Portanto, ela remete à necessidade da busca do sentido da vida, de uma nova maneira de ser, de um novo modo de conhecer, de fazer e de conviver, por meio das relações entre os diversos saberes e as culturas da humanidade. Ela representa a possibilidade de articulação da objetividade e da subjetividade, da ordem e da desordem, do sujeito e do objeto, da razão e da emoção (MORIN, 2019).

Ante o exposto, cumpre ressaltar que tanto Freire quanto Morin indicam a necessidade de se repensar paradigmas educacionais calcados na cristalização de padrões fragmentados, reproduzidos para estudantes que não são considerados em sua multidimensionalidade. Portanto, compreende-se que a previsibilidade, a homogeneidade, a ordem que ainda caracterizaram o processo educativo entram em choque com a imprevisibilidade, a heterogeneidade e o caos que se fazem presentes nas relações humanas.

\section{Metodologia}

Esta pesquisa considera, prioritariamente, os preceitos da abordagem qualitativa. Essa abordagem considera o universo de 
significados, motivos, aspirações, crenças, valores e atitudes, correspondendo "[...] a um espaço mais profundo das relações, dos processos e dos fenômenos que não podem ser reduzidos à operacionalização de variáveis" (MINAYO, 2010, p. 23).

Como método, optou-se pelo estudo bibliográfico para atender ao propósito principal de realizar o mapeamento das produções vinculadas a cursos brasileiros de pós-graduação stricto sensu com foco em Edgar Morin e Paulo Freire, com destaque para suas contribuições em relação à formação docente e a práticas pedagógicas articuladas às demandas que se expressam local e globalmente. Considerando esse propósito, a busca e a seleção das pesquisas foram feitas no Catálogo de Teses e Dissertações da CAPES. ${ }^{2}$

Em relação ao desenvolvimento desta pesquisa, a primeira consulta, usando independentemente como descritores os dois autores, considerou todas as publicações do catálogo, sem a aplicação de nenhum dos filtros de busca disponíveis, o que levou a um total de: i) Edgar Morin: 4.462 dissertações e 1.974 teses; ii) Paulo Freire: 23.1167 dissertações e 113.203 teses.

Dados os propósitos deste trabalho, fez-se, então, o recorte, selecionando-se os anos de 2020 e 2021 para a análise, o que reduziu os números para: i) Edgar Morin: 114 dissertações e 73 teses; ii) Paulo Freire: 5.467 dissertações e 3.026 teses. Quando aplicado o filtro de Área do Conhecimento "Educação", o número foi reduzido para: i) Edgar Morin: 27 dissertações e 14 teses; ii) Paulo Freire: 470 dissertações e 238 teses.

Com essa amostra, foram utilizados filtros para a seleção de pesquisas que apresentassem em seus títulos uma relação dos teóricos com a formação docente ou com a prática pedagógica, o que reduziu o número de estudos vinculadas a Edgar Morin para 7 pesquisas. Apesar de esse número ser superior em relação aos estudos vinculados a Paulo Freire, optou-se pela seleção das 7 primeiras pesquisas relacionadas a esse autor, para padronização comparativa. Com esse recorte estabelecido, o número de trabalhos ficou restrito a 14.

2 https://catalogodeteses.capes.gov.br/catalogo-teses/\#!/ 
Então, iniciou-se a análise dos dados, com o intuito de mapear nas teses e dissertações selecionadas os principais resultados apontados em relação às contribuições de Paulo Freire e Edgar Morin para a formação docente e para a prática pedagógica.

\section{Análise}

Dos autores dos 14 trabalhos selecionados, 10 são mulheres e 4 são homens. Em relação aos vínculos a programas de pós-graduação, 9 pesquisas vinculam-se ao Sul do país, 4 ao Sudeste e 1 ao Nordeste.

Quanto à abordagem, todos os trabalhos são classificados por seus autores como pesquisas qualitativas, com aplicação de: i) estudo de caso único, ii) estudo de casos múltiplos, iii) pesquisa-ação, iv) e pesquisa bibliográfica. Essa predominância de pesquisas qualitativas confirma a consolidação de uma tendência iniciada nas décadas de 1980 e 1990 no campo da Educação. De acordo com André (2001, p. 54), elas “[...] englobam um conjunto heterogêneo de perspectivas, de métodos, de técnicas e de análises [...]”, trazendo para as pesquisas nessa área diferentes aplicações que possibilitam investigar os mais variados contextos.

Buscando atender o objetivo desta pesquisa, realizou-se a análise das 14 publicações destacando-se os resultados e as conclusões conforme apontados pelos autores das pesquisas. Desse modo, sistematizam-se nos Quadros 1 e 2, respectivamente, as contribuições de Freire e as de Morin. 


\section{Quadro 1 - Objetivos, resultados e conclusões das pesqui- sas sobre Freire analisadas}

\begin{tabular}{|c|c|c|c|}
\hline Autor & Objetivo & Resultados & Conclusões \\
\hline $\begin{array}{l}\text { Fernandes } \\
(2020)\end{array}$ & $\begin{array}{l}\text { Desenvolver e descre- } \\
\text { ver um projeto para } \\
\text { o ensino das lutas na } \\
\text { escola pautado na } \\
\text { proposta educacional } \\
\text { de Paulo Freire. }\end{array}$ & $\begin{array}{l}\text { A práxis Freiriana ficou } \\
\text { evidente na mudança de } \\
\text { comportamentos e de } \\
\text { posturas opressivas por parte } \\
\text { de alguns alunos, os quais } \\
\text { passaram a ver os demais co- } \\
\text { legas como iguais, com mais } \\
\text { empatia e como merecedores } \\
\text { de respeito. Portanto, pode- } \\
\text { mos afirmar que passaram } \\
\text { a ser mais tolerantes com as } \\
\text { diferenças. }\end{array}$ & $\begin{array}{l}\text { Necessidade de } \\
\text { reformulações na } \\
\text { Educação Física } \\
\text { brasileira, sendo } \\
\text { necessário superar } \\
\text { estigmas e precon- } \\
\text { ceitos. }\end{array}$ \\
\hline $\begin{array}{l}\text { Gonçalves } \\
(2021)\end{array}$ & $\begin{array}{l}\text { Investigar os saberes } \\
\text { necessários de forma- } \\
\text { dores para o desenvol- } \\
\text { vimento de uma prática } \\
\text { colaborativa no espaço } \\
\text { escolar de acordo com } \\
\text { os referenciais Frei- } \\
\text { rianos. }\end{array}$ & $\begin{array}{l}\text { Elaboração de indicadores } \\
\text { para o fortalecimento da } \\
\text { ação formativa da coorde- } \\
\text { nação e supervisão escolar, } \\
\text { pautada pela colaboração } \\
\text { proposta por Freire. }\end{array}$ & $\begin{array}{l}\text { Os saberes ne- } \\
\text { cessários aos } \\
\text { formadores para } \\
\text { a prática forma- } \\
\text { tiva colaborativa } \\
\text { podem ser organi- } \\
\text { zados pelas carac- } \\
\text { terísticas da Teoria } \\
\text { da Ação Dialógica. }\end{array}$ \\
\hline $\begin{array}{l}\text { Andrade } \\
(2020)\end{array}$ & $\begin{array}{l}\text { Investigar a presença } \\
\text { do pensamento de } \\
\text { Paulo Feire nos cursos } \\
\text { de Licenciatura de uma } \\
\text { universidade privada do } \\
\text { Vale dos Sinos. }\end{array}$ & $\begin{array}{l}\text { Essa informação não consta } \\
\text { no resumo. }\end{array}$ & $\begin{array}{l}\text { Freire apresenta-se } \\
\text { como um autor } \\
\text { indispensável para } \\
\text { uma formação } \\
\text { humanizadora. }\end{array}$ \\
\hline $\begin{array}{l}\text { Zanette } \\
(2020)\end{array}$ & $\begin{array}{l}\text { Investigar as contribui- } \\
\text { ções de Paulo Freire, } \\
\text { na compreensão de } \\
\text { seus orientandos, como } \\
\text { professor e orientador } \\
\text { na Pós-graduação stricto } \\
\text { sensu em Educação } \\
\text { como fundamento } \\
\text { teórico-prático para a } \\
\text { docência no Ensino } \\
\text { Superior. }\end{array}$ & $\begin{array}{l}\text { Construção de categorias } \\
\text { e subcategorias que nos } \\
\text { permitiram levantar as con- } \\
\text { tribuições de Paulo Freire } \\
\text { para a práxis docente na } \\
\text { Pós-Graduação stricto sensu } \\
\text { em Educação }\end{array}$ & $\begin{array}{l}\text { A presença amo- } \\
\text { rosa e com rigor } \\
\text { científico em sala } \\
\text { de aula e nas } \\
\text { orientações e no } \\
\text { educar pelo exem- } \\
\text { plo são aspectos } \\
\text { de extrema impor- } \\
\text { tância deixados } \\
\text { por Freire para a } \\
\text { educação. }\end{array}$ \\
\hline
\end{tabular}




\begin{tabular}{|c|c|c|c|}
\hline $\begin{array}{c}\text { Paz } \\
(2020)\end{array}$ & $\begin{array}{l}\text { Evidenciar e analisar } \\
\text { criticamente as neces- } \\
\text { sidades formativas dos } \\
\text { supervisores escolares } \\
\text { da Rede Municipal de } \\
\text { Ensino de São Paulo, } \\
\text { tendo em vista acenar } \\
\text { com uma proposta de } \\
\text { formação permanente } \\
\text { de supervisores, a partir } \\
\text { de categorias do refe- } \\
\text { rencial teórico de Freire. }\end{array}$ & $\begin{array}{l}\text { Categorias freirianas que se } \\
\text { constituem em diretrizes para } \\
\text { a elaboração de uma propos- } \\
\text { ta de formação permanente } \\
\text { de supervisores escolares que } \\
\text { venha a ser construída cole- } \\
\text { tivamente, pelos supervisores } \\
\text { em uma perspectiva crítico- } \\
\text {-emancipadora, com vistas } \\
\text { à melhoria da qualidade de } \\
\text { educação nas escolas. }\end{array}$ & $\begin{array}{l}\text { Os superviso- } \\
\text { res escolares não } \\
\text { possuem em } \\
\text { seu cotidiano } \\
\text { espaço-tem po } \\
\text { de formação } \\
\text { permanente para } \\
\text { a reflexão sobre } \\
\text { as suas práticas. }\end{array}$ \\
\hline $\begin{array}{c}\text { Marques } \\
(2020)\end{array}$ & $\begin{array}{l}\text { Analisar como a peda- } \\
\text { gogia desenvolvida por } \\
\text { Paulo Freire vem sendo } \\
\text { incorporada em artigos } \\
\text { sobre educação e tecno- } \\
\text { logia, examinando, so- } \\
\text { bretudo, sua aderência a } \\
\text { trabalhos críticos. }\end{array}$ & $\begin{array}{l}\text { Identificamos, nos trabalhos, } \\
\text { que a obra de Freire está } \\
\text { atrelada a discussões sobre } \\
\text { processos de ensino e apren- } \\
\text { dizagem com tecnologias; } \\
\text { formação de professores } \\
\text { para o uso das tecnologias } \\
\text { a partir das transformações } \\
\text { ocorridas na sociedade; de- } \\
\text { senvolvimento do currículo } \\
\text { escolar com tecnologias, por } \\
\text { meio de temas geradores e } \\
\text { valores da sustentabilidade } \\
\text { baseada em CTS. }\end{array}$ & $\begin{array}{l}\text { Compreendemos } \\
\text { que os autores que } \\
\text { recorrem à obra } \\
\text { de Freire para tra- } \\
\text { tar de tecnologia } \\
\text { e educação, em } \\
\text { sua maioria, fazem } \\
\text { uso de sua obra e } \\
\text { de suas categorias } \\
\text { para realizar uma } \\
\text { análise crítica desta } \\
\text { relação. }\end{array}$ \\
\hline $\begin{array}{l}\text { Vieira } \\
(2020)\end{array}$ & $\begin{array}{l}\text { Analisar o papel das re- } \\
\text { lações humanas na for- } \\
\text { mação docente a partir } \\
\text { de conceitos-chave de } \\
\text { Paulo freire e Humber- } \\
\text { to Maturana. }\end{array}$ & $\begin{array}{l}\text { As relações humanas são } \\
\text { formativas. Os professores } \\
\text { em formação inicial precisam } \\
\text { de contato próximo com o } \\
\text { cenário em que vão atuar } \\
\text { para desenvolver os saberes } \\
\text { intrínsecos a sua profissão. }\end{array}$ & $\begin{array}{l}\text { O amor e a amo- } \\
\text { rosidade se tornam } \\
\text { papel formativo no } \\
\text { estabelecimento } \\
\text { das relações hu- } \\
\text { manas e na conse- } \\
\text { quente formação } \\
\text { de professores. }\end{array}$ \\
\hline
\end{tabular}

Fonte: Gonçalves (2021), Andrade (2021), Zanette (2020), Paz (2020), Marques (2020), Fernandes (2020), Vieira (2020).

Em relação aos objetivos, nos trabalhos que se alicerçam nos pensamentos de Freire, encontramos preocupações relacionadas à inserção de suas ideias nos processos formativos, bem como pesquisas que se propõem a construir processos formativos pautados 
em Freire. Um dos exemplos é a proposta de Fernandes (2020), que buscou desenvolver um projeto para o ensino de luta nas escolas, tendo como base a perspectiva educacional de Paulo Freire.

Três pesquisas, de Fernandes (2020), Gonçalves (2021) e Paz (2020), desenvolveram-se na Educação Básica, e os pesquisadores buscaram apontar como o pensamento freiriano pode contribuir para a formação de professores que atuam nesse nível de ensino. No Ensino Superior, as pesquisas de Andrade (2021) e Vieira (2020) apontaram a necessidade de a formação inicial de docentes ser mais humanizadora, para isso apresentam as ideias de Freire como um caminho para que essa humanização se concretize. Já Zanette (2020) abordou a necessidade da presença amorosa na pós-graduação e realizou sua pesquisa com participantes que foram orientandos de Freire.

Sobre a amorosidade no processo educativo, Freire (2019, p. 142) registrou: “[...] como prática estritamente humana jamais pude entender a educação como uma experiência fria e sem alma, em que os sentimentos e as emoções, os desejos devessem ser reprimidos por uma espécie de ditadura racionalista." Em suas obras, entrevistas e palestras, o autor sempre buscou apontar a necessidade de o processo educativo estar pautado em preceitos de amorosidade e respeito entre educador e educando, nunca deixando de lado a seriedade, o rigor e a disciplina intelectual. Assim, as pesquisas analisadas, feitas tanto no Ensino Superior como na Educação Básica, apontam em seus resultados e conclusões que a amorosidade tem importante papel formativo na educação.

A pesquisa de Marques (2020), por sua vez, buscou identificar como as ideias de Freire são abordadas em estudos que tratam de tecnologia. Marques conclui a necessidade de os docentes conhecerem a realidade na qual irão atuar.

Zanette (2020) apresentou categorias freirianas para uma proposta formativa. Gonçalves (2021) elaborou indicadores para o fortalecimento das ações formativas. As demais pesquisas apontaram a necessidade de se repensar e reestruturar o processo formativo, buscando, nas palavras de Freire (2019, p. 143), formar "[...] gente mais gente".

A seguir, acompanhe no Quadro 3 as sínteses das pesquisas sobre Morin. 


\section{Quadro 2-Objetivos, resultados e conclusões das pesquisas sobre Morin analisadas}

\begin{tabular}{|c|c|c|c|}
\hline Autor & Objetivos & Resultados & Conclusões \\
\hline $\begin{array}{l}\text { Martinelli } \\
(2020)\end{array}$ & $\begin{array}{l}\text { Articular os construtos } \\
\text { apresentados na encí- } \\
\text { clica Laudato si, do Papa } \\
\text { Francisco, no pensamen- } \\
\text { to complexo de Edgar } \\
\text { Morin e na proposta de } \\
\text { complexidade ambiental } \\
\text { de Enrique Leff como } \\
\text { subsídios para uma for- } \\
\text { mação inicial de professo- } \\
\text { res, visando à preparação } \\
\text { para docência com visão } \\
\text { de ecologia integral. }\end{array}$ & $\begin{array}{l}\text { A importância das } \\
\text { contribuições do } \\
\text { pensamento complexo } \\
\text { de Edgar Morin, junto } \\
\text { das concepções de crise } \\
\text { ambiental, racionalida- } \\
\text { de ambiental e saber } \\
\text { ambiental de Enrique } \\
\text { Leff, para } \\
\text { a construção de uma } \\
\text { formação de profes- } \\
\text { sores para a ecologia } \\
\text { integral, como solicita } \\
\text { o Papa Francisco na } \\
\text { encíclica Laudato si. }\end{array}$ & $\begin{array}{l}\text { A pesquisa pode contri- } \\
\text { buir para a elaboração de } \\
\text { propostas dinâmicas de } \\
\text { formação de professores } \\
\text { pertencentes às diversas } \\
\text { áreas do conhecimento, } \\
\text { alimentando o sonho } \\
\text { de que o respeito ao } \\
\text { ambiente, à vida, à ética } \\
\text { planetária venha a se } \\
\text { tornar realidade. }\end{array}$ \\
\hline $\begin{array}{l}\text { Knapik } \\
(2020)\end{array}$ & $\begin{array}{l}\text { Analisar como os saberes } \\
\text { da Educação do Futuro } \\
\text { podem contribuir para } \\
\text { os projetos pedagógicos } \\
\text { da instituição investi- } \\
\text { gada, bem como para a } \\
\text { formação e atuação dos } \\
\text { professores. }\end{array}$ & $\begin{array}{l}\text { Os saberes da Edu- } \\
\text { cação do Futuro, } \\
\text { apontados por Edgar } \\
\text { Morin, constituem } \\
\text { uma importante con- } \\
\text { tribuição pedagógica e } \\
\text { epistemológica para a } \\
\text { formação dos docentes } \\
\text { e discentes. }\end{array}$ & $\begin{array}{l}\text { Propõe-se que a institui- } \\
\text { ção pesquisada considere } \\
\text { a possibilidade de acolhi- } \\
\text { mento do pensamento } \\
\text { complexo em seus } \\
\text { projetos pedagógicos, na } \\
\text { formação de seus profes- } \\
\text { sores e na prática educa- } \\
\text { tiva de seus alunos. }\end{array}$ \\
\hline Pinto (2020) & $\begin{array}{l}\text { Propor a criação de } \\
\text { instrumentos de coletas } \\
\text { de dados para a avaliação } \\
\text { à luz da teoria da com- } \\
\text { plexidade. }\end{array}$ & $\begin{array}{l}\text { Sustentamos que uma } \\
\text { apresentação textual de } \\
\text { contextualização opor- } \\
\text { tuniza ao aluno, além de } \\
\text { presença e familiarida- } \\
\text { de, melhor compreen- } \\
\text { são interpretativa das } \\
\text { questões e melhores } \\
\text { possibilidades para } \\
\text { organizar e expressar } \\
\text { suas "respostas", sem } \\
\text { desmerecer a exigência } \\
\text { da seriedade e cientifi- } \\
\text { cidade. }\end{array}$ & $\begin{array}{l}\text { É possível compreender } \\
\text { que o processo } \\
\text { avaliativo, na perspectiva } \\
\text { da complexidade, } \\
\text { interconecta fazeres } \\
\text { educativos ao momento } \\
\text { da coleta de dados para } \\
\text { avaliação, firmando a } \\
\text { visão de que a parte } \\
\text { foi tecida e entrelaçada } \\
\text { ao todo, resultando na } \\
\text { compreensão de um } \\
\text { todo que é maior do que } \\
\text { a soma das partes. }\end{array}$ \\
\hline
\end{tabular}




\begin{tabular}{|c|c|c|c|}
\hline $\begin{array}{l}\text { Sant'ana } \\
(2020)\end{array}$ & $\begin{array}{l}\text { Analisar as possíveis } \\
\text { repercussões do pen- } \\
\text { samento complexo na } \\
\text { formação continuada de } \\
\text { professores da educação } \\
\text { básica, como subsídios } \\
\text { para práticas pedagógicas } \\
\text { inovadoras. }\end{array}$ & $\begin{array}{l}\text { Foi possível identificar } \\
\text { que o curso on-line } \\
\text { propiciou análises e } \\
\text { reflexões aos docentes } \\
\text { participantes da pes- } \\
\text { quisa, as quais oportu- } \\
\text { nizaram aproximações } \\
\text { com as proposições } \\
\text { do pensamento com- } \\
\text { plexo, as quais podem } \\
\text { servir de embasamento } \\
\text { teórico para alavancar } \\
\text { a formação pedagógica } \\
\text { continuada de professo- } \\
\text { res, bem como instigar } \\
\text { novas práticas de } \\
\text { ensino mais adequadas } \\
\text { ao século XXI. }\end{array}$ & $\begin{array}{l}\text { É evidente a } \\
\text { pertinência de os } \\
\text { professores procurarem } \\
\text { constantemente } \\
\text { revalidar os saberes } \\
\text { docentes concernentes } \\
\text { a uma educação mais } \\
\text { equalizada aos anseios } \\
\text { desta geração de } \\
\text { estudantes. A inovação } \\
\text { dos processos didáticos } \\
\text { não se dá apenas por } \\
\text { modismos, mas por } \\
\text { intermédio da reflexão } \\
\text { crítica, objetivando } \\
\text { a transformação do } \\
\text { contexto social e } \\
\text { educacional. }\end{array}$ \\
\hline $\begin{array}{l}\text { Carvalho } \\
(2020)\end{array}$ & $\begin{array}{l}\text { Desenvolver uma in- } \\
\text { vestigação no intuito de } \\
\text { conhecer as proposições } \\
\text { da utilização de meto- } \\
\text { dologias integradoras, } \\
\text { por meio de unidades } \\
\text { curriculares com viés de } \\
\text { PI, bem como estudar } \\
\text { qual a finalidade de se } \\
\text { interligar e contextualizar } \\
\text { as diferentes categorias de } \\
\text { conhecimentos que estão } \\
\text { propiciando a evolução } \\
\text { acadêmica dos estudantes. }\end{array}$ & $\begin{array}{l}\text { Precisamos estar } \\
\text { dispostos a pensar de } \\
\text { maneira mais ampla, } \\
\text { considerar emergências, } \\
\text { ambivalências e contri- } \\
\text { buições de diferentes } \\
\text { autores e de várias } \\
\text { abordagens das ciências. } \\
\text { Os especialistas pre- } \\
\text { cisam dialogar e criar } \\
\text { possibilidades de recur- } \\
\text { sividade para a constru- } \\
\text { ção de conhecimentos, } \\
\text { pois, no final, os seres } \\
\text { humanos são produtos } \\
\text { e produtores ao mesmo } \\
\text { tempo. Elaborar um } \\
\text { conhecimento pertinen- } \\
\text { te é uma consideração } \\
\text { necessária para a atual } \\
\text { educação }\end{array}$ & $\begin{array}{l}\text { Os envolvidos na ação } \\
\text { educacional necessitam } \\
\text { de uma visão hologramá- } \\
\text { tica, recursiva e dialógica, } \\
\text { tecendo um conhe- } \\
\text { cimento que entenda } \\
\text { as partes, mas que, de } \\
\text { forma inter-relacional, se } \\
\text { construa um saber com } \\
\text { olhar que compreende } \\
\text { o disciplinar, efetue o } \\
\text { interdisciplinar e alcance } \\
\text { o transdisciplinar. }\end{array}$ \\
\hline
\end{tabular}




\begin{tabular}{|c|c|c|c|}
\hline Soave (2020) & $\begin{array}{l}\text { Propor a religação dos } \\
\text { saberes cuidado de si e } \\
\text { autoética, como contri- } \\
\text { buição para uma atuação } \\
\text { docente que, para além } \\
\text { das implicações da bio- } \\
\text { política, possa se inspirar } \\
\text { em possíveis horizontes } \\
\text { da educação na Comple- } \\
\text { xidade. }\end{array}$ & $\begin{array}{l}\text { A religação do cuidado } \\
\text { de si com a autoética } \\
\text { traz outras perspectivas } \\
\text { para além da biopolí- } \\
\text { tica que, inspirada em } \\
\text { possíveis horizontes da } \\
\text { complexidade, contribui } \\
\text { com saberes a serem } \\
\text { incorporados à forma- } \\
\text { ção inicial e continuada } \\
\text { dos docentes, conec- } \\
\text { tando um conjunto de } \\
\text { significados e sentidos } \\
\text { presentes nas duas } \\
\text { concepções teóricas. }\end{array}$ & $\begin{array}{l}\text { A proposta da religação } \\
\text { dos saberes cuidado de } \\
\text { si e autoética na atuação } \\
\text { docente, como objetivo } \\
\text { geral, é uma possibilida- } \\
\text { de a ser agregada, entre- } \\
\text { laçada, bem como um } \\
\text { desafio paradigmático } \\
\text { a ser superado. Não se } \\
\text { trata de um método, mas } \\
\text { de reflexão, de tentativa, } \\
\text { de novo olhar diante de } \\
\text { um mundo ávido por } \\
\text { mudanças. }\end{array}$ \\
\hline Arraes (2020) & $\begin{array}{l}\text { Analisar criticamente as } \\
\text { contribuições do recur- } \\
\text { so de aprendizagem, o } \\
\text { jogo Escolhas \& Acaso, } \\
\text { que possa auxiliar na } \\
\text { compreensão de valores } \\
\text { morais na visão da com- } \\
\text { plexidade e da transdisci- } \\
\text { plinaridade junto a alunos } \\
\text { do ensino médio. }\end{array}$ & $\begin{array}{l}\text { Percebeu-se que é pre- } \\
\text { ciso compreender que } \\
\text { o futuro já não é mais } \\
\text { só dos jovens, e atribuir } \\
\text { a responsabilidade } \\
\text { somente ao outro, as } \\
\text { ações necessárias com } \\
\text { o pensar transformador } \\
\text { são para agora. }\end{array}$ & $\begin{array}{l}\text { O jogo numa perspec- } \\
\text { tiva transdisciplinar é } \\
\text { uma opção de recurso } \\
\text { de aprendizagem com } \\
\text { o intuito de estimular } \\
\text { o desenvolvimento de } \\
\text { saberes, na perspectiva } \\
\text { complexa e transdisci- } \\
\text { plinar, pertinentes aos } \\
\text { jovens adolescentes no } \\
\text { ensino médio. }\end{array}$ \\
\hline
\end{tabular}

Fonte: Martinelli (2020), Knapik (2020), Pinto (2020), Sant'ana (2020), Carvalho (2020), Soave (2020), Arraes (2020).

Nos estudos alicerçados nas ideias de Morin, 4 possuem como campo de pesquisa o ensino superior, Martinelli (2020), Knapik (2020), Carvalho (2020) e Soave (2020). Eles apontam, em seus objetivos, a articulação do pensamento de Morin com outros autores para embasar propostas formativas na formação inicial de docentes. Buscam também investigar como os saberes propostos por Morin podem contribuir com essa formação.

Nesse aspecto, Knapik (2020) e Carvalho (2020) apresentam em seus resultados a necessidade de se repensar o processo formativo, pois compreendem que uma mudança paradigmática está ocorrendo e que esta somente se efetivará por meio da educação. 
Sobre esse assunto, Morin (2018, p. 92) fala da reforma do pensamento que "[...] vai gerar um pensamento do contexto e do complexo. Vai gerar um pensamento que liga e enfrenta a incerteza”. Diante disso, as pesquisas analisadas apontam para a importância de inserir nos processos formativos características do pensamento complexo, para que possamos colaborar com a formação de pessoas mais humanas e com maior capacidade de compreender o todo sem subestimar a relevância das partes.

A pesquisas de Pinto (2020), Sant'ana (2020) e Arraes (2020) inserem-se na Educação Básica. Apesar de seus enfoques diferenciados, elas apresentam em seus objetivos o compromisso de analisar as contribuições do pensamento complexo e repensar as práticas pedagógicas. Tais pesquisas trazem como resultados e conclusões a pertinência das ideias de Morin para que o processo educacional seja repensado e reformulado. Sant'ana (2020) apresenta como recurso uma formação on-line, buscando despertar reflexões nos docentes a respeito de sua prática pedagógica. Já Arraes (2020) apresenta um jogo denominado "Escolhas \& Acasos" como recurso pedagógico para trabalhar de maneira transdisciplinar.

Ao transitar pelas pesquisas, reitera-se a necessidade de reflexões sobre a missão do ensino. Nesse sentido, Morin (2018, p. 11) alerta que é necessário mobilizar "[...] uma cultura que permita compreender nossa condição e nos ajude a viver, e que favoreça, ao mesmo tempo, um modo de pensar aberto e livre."

Por isso, a relevância de formações e práticas pedagógicas que ultrapassem a simples transmissão de conteúdo, trocando esse referencial secular por iniciativas que favoreçam a reflexão e a crítica, além do compromisso em atuar para protagonizar mudanças. Assim como Morin e Delgado (2017), defendemos a emergência de atuar sobre e a realidade e advogamos não por uma esperança ilusória e salvadora, mas utópica e criadora, ativadora e generadora.

\section{Considerações finais}

A necessidade de ressignificar a formação inicial e continuada dos docentes se aprofundou com a pandemia causada pelo SARS-CoV-2. Se antes já se observava um distanciamento entre as 
ênfases formativas e as demandas do contexto de atuação, com a realidade vivenciada a partir de 2020, a ruptura defendida por Freire (2019) nas reflexões sobre a perspectiva bancária e a necessidade de superar o pensamento reducionista, que "[...] rompe o complexo do mundo em fragmentos disjuntos, fraciona os problemas, separa o que está unido [...]", conforme alerta Morin (2011, p. 40), transformaram-se em condições nodais para os processos formativos que se comprometam com a realidade atual e as incertezas em relação ao futuro da humanidade.

Assim, a análise das pesquisas que envolveram as contribuições teóricas de Morin e Freire evidenciou convergências em importantes subsídios para a formação docente e para as práticas pedagógicas. Essas convergências reiteram a perspectiva de Nóvoa (2019) a respeito de iniciativas que envolvam o contexto de atuação dos professores, para que, no coletivo, possa haver respostas aos desafios impossíveis de serem enfrentados pela perspectiva fragmentada e atomizada da educação.

Nos estudos realizados, percebe-se que a dialogicidade encontrada nas palavras de Morin conflui com pensamentos de Freire (2019, p. 25), especialmente quando este afirma que "[...] embora diferentes entre si, quem forma se forma e se re-forma ao formar e quem é formado forma-se ao ser formado." Por meio disso, denota-se que ambos os autores compreendem que o processo formativo impacta os docentes e que isso reflete em suas ações pedagógicas.

Especificamente em relação aos objetivos, nos trabalhos que se alicerçaram nos pensamentos de Freire, as preocupações foram relacionadas à inserção de suas ideias nos processos formativos e à construção de processos formativos pautados nesse autor. Já os estudos com foco em Morin demonstraram preocupações em articular seu pensamento a outros autores para embasar propostas de formação inicial de docentes; essas pesquisas também se comprometeram em averiguar como os saberes discutidos pelo autor podem contribuir com tal formação.

Outro aspecto de destaque nas análises das pesquisas sobre ambos os autores caracteriza-se pela defesa de a educação ser re- 
pensada de forma abrangente. Para Freire (2013), essa necessidade tem como horizonte a formação de pessoas críticas que reconheçam o poder transformador de seu papel como cidadãos. Morin, por sua vez, destaca a relevância de uma prática pedagógica que se comprometa em contextualizar e globalizar conhecimentos, indicando, como necessidade vital da era planetária, um pensamento capaz de unir e diferenciar os conhecimentos (2010), esperando da realidade o inesperado e trabalhando pelo improvável (2011).

Tanto a revisão das contribuições de Morin e Freire quanto a análise das pesquisas indicam não apenas convergências entre os autores - que se aproximam pelo compromisso com a educação -, mas também aspectos que acentuam condições específicas. SeEdgar Morin vivenciou a transição do século XX ao XXI e tem convivido com o acelerar das transformações que assolam o planeta, possibilitando-lhe continuar com suas contribuições reflexivas sobre as incertezas atuais, Freire deixou um legado incontestável para a educação, o que faz de ambos referências fundamentais para a compreensão da emergência de uma metamorfose no campo educacional.

\section{Referências}

ANDRADE, D. S. A presença de Paulo Freire nos cursos de licenciatura de uma universidade do Vale do Sinos/RS: contribuições para uma formação humanizadora. 2021. Dissertação (Mestrado em Educação) - Universidade do Vale do Rio dos Sinos - UNISINOS, São Leopoldo, 2021.

ANDRE, M. A etnografia na prática escolar. Campinas: Papirus, 2001.

ARRAES, L. G. M. Desenvolvimento formativo de valores morais à luz da visão da complexidade e da transdisciplinaridade para recursos de aprendizagem. 2020. Dissertação (Mestrado em Educação) - Pontifícia Universidade Católica do Paraná - PUCPR, Curitiba, 2020.

CARVALHO, C. W. Proposta pedagógica integradora no Curso de Bacharelado em Administração da Faculdade de Balsas/MA à luz do pensamento complexo. 2020. Dissertação (Mestrado em Educação nas Ciências) - Universidade Regional do Noroeste do Estado Do Rio Grande do Sul - UNUJUí, Ijuí, 2020 . 
FERNANDES, F. F. D. A prática pedagógica das lutas na escola: um projeto pautado na proposta freireana. 2020. Dissertação (Mestrado em Educação Universidade Federal Do Ceará - UFC, Fortaleza, 2020.

FREIRE, P. Pedagogia da autonomia: saberes necessários à prática educativa. Rio de Janeiro: Paz e Terra, 2013.

FREIRE, P. Pedagogia do oprimido. 75. ed. Rio de Janeiro: Paz e Terra, 2019.

GATTI, B. A. Formação de professores, complexidade e trabalho docente. Rev. Diálogo Educ., Curitiba, v. 17, n. 53, p. 721-737, 2017. DOI: https://doi.org/10.7213/1981-416X.17.052.AO01. Disponível em: https://periodicos.pucpr. br/index.php/dialogoeducacional/article/viewFile/8429/17739. Acesso em: 16 nov. 2019.

GONÇALVES, W. T. A formação colaborativa no trabalho de coordenação pedagógica e supervisão escolar: referenciais freireanos. 2021. Dissertação (Mestrado Profissional em Educação: formação de formadores Instituição de Ensino) - Pontifícia Universidade Católica de São Paulo - PUC-SP, São Paulo 2021.

KNAPIK, M. J. Educação na perspectiva da complexidade: contribuições pedagógicas e epistemológicas para uma instituição de educação superior confessional. 2020. Dissertação (Mestrado em Educação) - Pontifícia Universidade Católica do Paraná - PUCPR, Curitiba, 2020.

MARQUES, S. E. C. Educação e tecnologia com referencial de Paulo Freire: uma relação (in)comum. 2020. Dissertação (Mestrado em Educação) - Universidade Estácio de Sá, Rio de Janeiro, 2020.

MARTINELLI, L. M. B. A formação dos professores subsidiada pela concepção da teoria da complexidade e visão da ecologia integral, 2020. Tese (Doutorado em Educação) - Pontifícia Universidade Católica do Paraná - PUCPR, Curitiba, 2020.

MINAYO, M. C. S. Pesquisa social: teoria, método e criatividade. 29. ed. Petrópolis: Vozes, 2010.

MORAES, M. C.; TORRE, S. de la. Sentipensar: fundamentos e estratégias para reencantar educação. Petrópolis, RJ: Vozes, 2007.

MORIN, E. A cabeça bem-feita: repensar a reforma, reformar o pensamento. Tradução de Eloá Jacobina. 24. ed. Rio de Janeiro: Bertrand Brasil, 2018. 
MORIN, E. A via para o futuro da humanidade. Tradução de Edgard de Assis Carvalho e Mariza Perassi Bosco. 2. ed. Rio de Janeiro: Bertrand Brasil, 2013.

MORIN, E. Ciência com consciência. Tradução de Maria D. Alexandre e Maria Alice Sampaio Dória. 18. ed. Rio de Janeiro: Berhand, 2019.

MORIN, E. Introdução ao pensamento complexo. Tradução de Eliane Lisboa. 5. ed. Porto Alegre: Sulina, 2015.

MORIN, E. Os sete saberes necessários à educação do futuro. 2. ed. rev. Tradução de Eleonora F. da Silva e Jeanne Sawaya. São Paulo: Cortez, 2011.

MORIN, E.; DELGADO DÍAZ, C. J. Reinventar la educación: abrir caminos a la metamorphosis de la humanidad. Havana: UH, 2017.

NICOLESCU, B. Manifesto da transdisciplinaridade. 3. ed. Tradução de Lucia Pereira de Souza. São Paulo: Triom, 2018.

NÓVOA, A. Firmar a posição como professor, afirmar a profissão docente. Cadernos de Pesquisa, v. 47, n. 166, p. 1106-1133, out./dez. 2017. Disponível em: http://www.scielo.br/pdf/cp/v47n166/1980-5314-cp-47-166-1106.pdf. Acesso em: 20 set. 2019.

NÓVOA, A. Os professores e a sua formação num tempo de metamorfose da escola. Educação \& Realidade, Porto Alegre, v. 44, n. 3, e84910, 2019. Disponível em: https://www.scielo.br/pdf/edreal/v44n3/2175-6236-edreal-44-03-e84910. pdf. Acesso em: 14 abr. 2021.

PAZ, A. O. R. A Formação permanente de supervisores escolares inspirada na pedagogia de Paulo Freire: desafios e possibilidades. 2020. Dissertação (Mestrado Profissional em Educação: formação de formadores) - Pontifícia Universidade Católica de São Paulo - PUC-SP, São Paulo, 2020.

PINTO, V. J. Avaliação do processo de ensino e de aprendizagem do/no Ensino Fundamental vista como dinamizadora na construção de conhecimentos, tendo como baluarte o pensamento complexo. 2020. Dissertação (Mestrado em Educação) - Universidade do Oeste de Santa Catarina - UNOESC, Joaçaba, 2020.

SANTANA, V. S. O pensamento complexo como subsídio na formação pedagógica continuada on-line. 2020. Dissertação (Mestrado em Educação) Pontifícia Universidade Católica do Paraná - PUCPR, Curitiba, 2020. 
SOAVE, C. Horizontes da complexidade: a religação dos saberes cuidado de si e autoética como contribuição à atuação docente. 2020. Tese (Doutorado em Educação) - Universidade de Caxias do Sul - UCS, Caxias do Sul, 2020.

VIEIRA, B. C. A formação de professores à luz das relações humanas: um estudo a partir de Freire e Maturana. 2020. Dissertação (Mestrado em Educação) - Universidade de São Paulo - USP, São Paulo

ZANETTE, M. Contribuições de Paulo Freire para a práxis docente na pós-graduação stricto sensu em Educação. 2020. Dissertação (Mestrado em Educação) - Universidade Comunitária da Região de Chapecó - UNOCHAPECÓ, Chapecó, 2020. 